\title{
Research on Shape Change of Multimaterial Electrode for EDM
}

\author{
Wenjian Wang, ${ }^{1}$ Yu Liu $\mathbb{D},{ }^{2}$ Wenchao Zhang $\mathbb{D}^{2},{ }^{2}$ Fujian Ma $\mathbb{D},{ }^{2}$ Dapeng Yang, \\ and Shengfang Zhang $\mathbb{D}^{2}$ \\ ${ }^{1}$ Shaanxi Railway Institute, Weinan 714000, China \\ ${ }^{2}$ School of Mechanical Engineering, Dalian Jiaotong University, Dalian 116028, China \\ Correspondence should be addressed to Yu Liu; liuyu_ly12@126.com
}

Received 23 July 2019; Revised 17 September 2019; Accepted 16 October 2019; Published 11 November 2019

Academic Editor: Antonio Caggiano

Copyright ( 2019 Wenjian Wang et al. This is an open access article distributed under the Creative Commons Attribution License, which permits unrestricted use, distribution, and reproduction in any medium, provided the original work is properly cited.

The shape change law of a multimaterial electrode in EDM was studied, and a cosimulation between ANSYS and MATLAB of electrode shape change of the multimaterial electrode and workpiece was established. Element birth and death in ANSYS was used to obtain the removal volume in a single-pulse discharge, and the electrode feed strategy, material removal, and renewal strategy are considered to establish the shape simulation strategy. Then, a program based on MATLAB software was compiled to simulate the machining process and predict the shape change of the multimaterial electrode of different combinations. The experiments of different multimaterial electrodes were carried out with the die steel as the workpiece. The simulation results were compared with the experimental results to verify the effectiveness of the simulation model.

\section{Introduction}

In aviation and aerospace, electronic communication, biomedical engineering, mold manufacturing, and many other technical fields, micro/meso complex surface parts are more and more widely used. Electrical discharge machining (EDM) is an effective method for machining small and complex surface parts of difficult-to-cut conductive materials. However, in some occasions, the shape of some small surface is very complex and the surface quality requirements are very high. The efficiency of traditional EDM layer milling is low because of redundant processing path of the complex layer processing, and the surface quality is not good because of overlapping tool marks. Multimaterial electrode EDM is a new method for fabricating micro/meso complex surface parts. By using the electrode wear and shape change of different material electrodes in EDM to achieve the machining shape requirements of different complex surface features and by combining various electrode materials into multimaterial forming electrodes, it can process micro/meso cavity with complex surfaces. And it has high production efficiency and good surface quality. Compared with the EDM layer milling method, the processing efficiency and surface quality of the complex surface are improved by using the adverse copy of the surface shape after the electrode wear. However, the electrode combination of different materials during machining will produce different wear and shape changes, which has a great influence on the machining accuracy of the surface. Different material compositions, physical properties, original shape, and other factors have certain influence on the processed shape, which is a side effect of processing complex surface in this way. In order to master the rule of shape change, better control the shape change in the process of machining, and meet the requirements of machining accuracy, it is necessary to obtain the rule of machining accuracy and shape change through simulation. Therefore, the electrode wear and shape change law of multimaterial electrodes in EDM are explored, which can provide theoretical support and technical reference for multimaterial electrodes forming machining of small complex surfaces in EDM [1-3].

In the study on the shape of the electrode in EDM, many scholars carried out effective work. Jeong et al. carried out a simulation model of EDM drilling process with a cylindrical electrode in order to predict the shape of the tool and the hole after drilling. The shape of the electrode and the hole could be predicted accurately [4]. Uhlmann et al. carried out experimental investigations to decrease the wear of tool 
electrodes by using boron doped CVD (B-CVD) diamond and polycrystalline diamond (PCD). The process behavior of $\mathrm{B}-\mathrm{CVD}$ and PCD in micro-EDM as well as influences of electrode materials on tool electrode wear and surface formation processes was studied [5]. Surleraux et al. introduced a new method for simulating the micro-EDM process in order to predict both the tool's wear and the workpiece's roughness, and the simulation method was validated through a comparison with experimental data [6]. $\mathrm{Yu}$ et al. presented a model and a simplified simulation algorithm. The experimental results of micro- and macroEDM generated surface profiles confirmed the validity of the proposed mathematical model and the simulation algorithm [7]. Pei et al. took the geometric model of an electrode and workpiece as a two-dimensional matrix to simulate the shape changes in the process of machining and carried out experimental verification. The results showed that the model could predict the contour of the electrode and workpiece very well when simulating fixed length compensation [8]. Lv et al. proposed the simulation model of microhole machining process based on composite electrode, wrote the simulation program with MATLAB software platform, and carried out the electrode shape simulation research [9]. Fu et al. proposed a simulation model of electrode wear based on MATLAB to predict the geometry appearance of tool and drilled hole. And the model was verified by actual experiments. Aimed at the electrode wear when machining the blind hole in EDM, on the basis of two-dimensional matrices, the shape change process of the electrode was simulated by setting the influence factors of electrode movement, discharge gap, removal amount of single-pulse material, and relative loss rate [10]. Khanra et al. developed the $\mathrm{ZrB}_{2}-\mathrm{Cu}$ composite by adding different amounts of $\mathrm{Cu}$ and tested it as a tool material at different process parameters of EDM during machining of mild steel. The $\mathrm{ZrB}_{2}-40$ wt.\% $\mathrm{Cu}$ composite shows more metal removal rate (MRR) with less tool removal rate (TRR) than commonly used $\mathrm{Cu}$ tool [11]. Mohri et al. presented a new method of surface modification using a composite structured electrode and showed that the electrode material in the work surface layer and the characteristics of the surface of raw material remarkably changed. These surfaces have less cracks and higher corrosion resistance and wear resistance [12].

In this paper, the shape change of a multimaterial electrode in EDM is studied. Element birth and death in ANSYS is used to obtain the removal volume in a singlepulse discharge. And the two-dimensional simulation model of the multimaterial electrode and workpiece is established with MATLAB software. The shape simulation strategy is established. The electrode feed strategy, material removal, and renewal strategy are considered. When the electrode is fed, the shortest distance between the bottom of the electrode and the workpiece is found to generate the discharge point, and the material is removed to simulate the shape change of the electrode and the shape change of the cavity in the actual processing. To predict the shape changes of various multimaterial electrodes under continuous discharge conditions, the influence parameters are as follows: single-pulse removal volume of different materials, relative wear ratio of electrode workpiece, electron escape work, etc. The machining experiment of the multimaterial electrode with different combinations is carried out to verify the validity of the simulation model.

\section{Multimaterial Electrode EDM Continuous Discharge Machining Model}

Multimaterial electrode EDM has the same principle as traditional EDM. The main difference lies in the change of the processing electrodes. Different materials of electrodes are combined into multimaterial electrodes. The different characteristics of the wear and shape change of different electrodes are used to complete the formation of complex microsurface processing. Multimaterial electrode EDM is shown in Figure 1.

2.1. Geometric Model Design of Multimaterial Electrode. It is a critical step for EDM continuous discharge simulation analysis to build an analyzable geometric model of a multimaterial electrode and workpiece of EDM. The discharge point of the electrode is determined by the distance between the electrode and workpiece under certain discharge parameters in the process of EDM. The electrode is a three-dimensional axisymmetric entity as a whole, so the discharge point will be evenly distributed on the end face of the electrode. According to the above analysis, in the simulation process, the influence of some unnecessary factors is ignored reasonably in order to reduce the amount of simulation calculation and the following assumptions are made: Figures 2 and 3

(1) The multimaterial electrode and the workpiece are both axisymmetric, and the three-dimensional electrode and the workpiece are simplified into two two-dimensional shapes to simulate the shape change. Figure 2 shows a working photograph of a multimaterial electrode, which is simplified as a twodimensional model separated by the center line as shown in Figure 3.

(2) The discharge point depends on the minimum discharge distance. When the minimum distance is reached on different materials at the same time, the material with small electron work function is preferentially discharged; when multiple minimum distances are reached simultaneously on the same kind of material, discharge points are randomly generated at many minimum distance positions.

(3) In each simulation of multimaterial electrode simulation, only one discharge crater is generated on each of the two electrodes and the volume of a single discharge is equal to the volume of crater obtained by single-pulse discharge. The removal of the electrode and the workpiece is determined by the relative wear ratio of the electrode and the workpiece.

(4) If there is an overlap in the volume removed by two discharges at adjacent positions, the overlap volume is subtracted. 


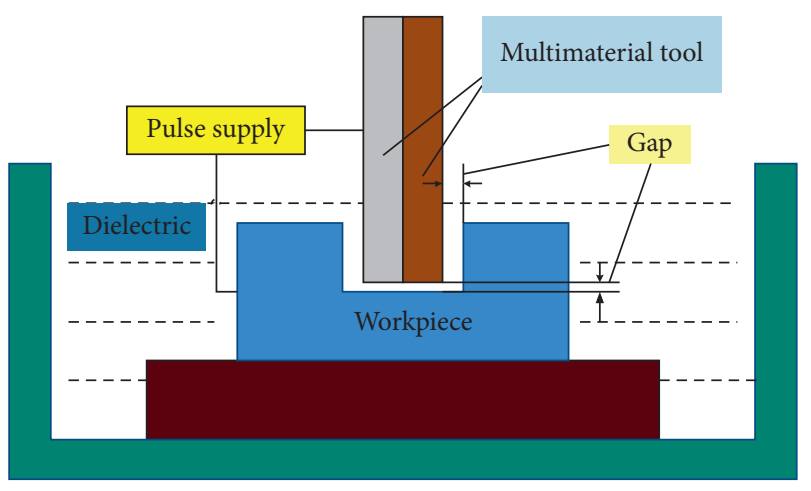

Figure 1: Multimaterial electrode EDM.

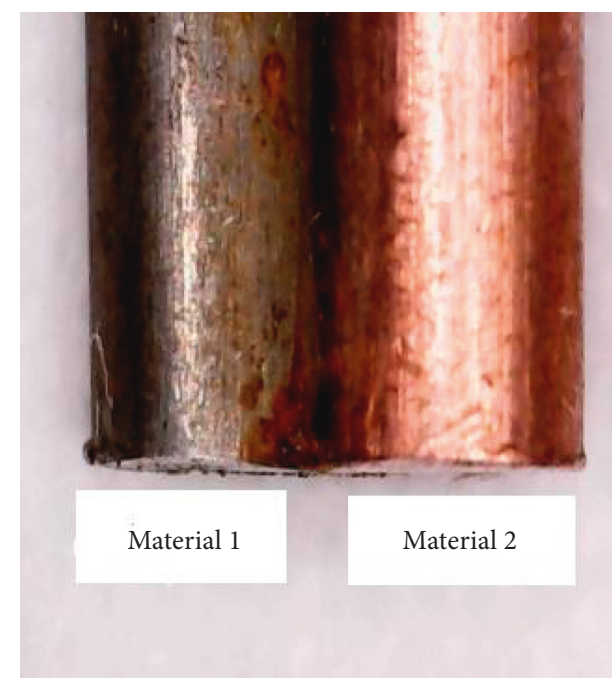

FIgURE 2: Multimaterial electrode work photos.

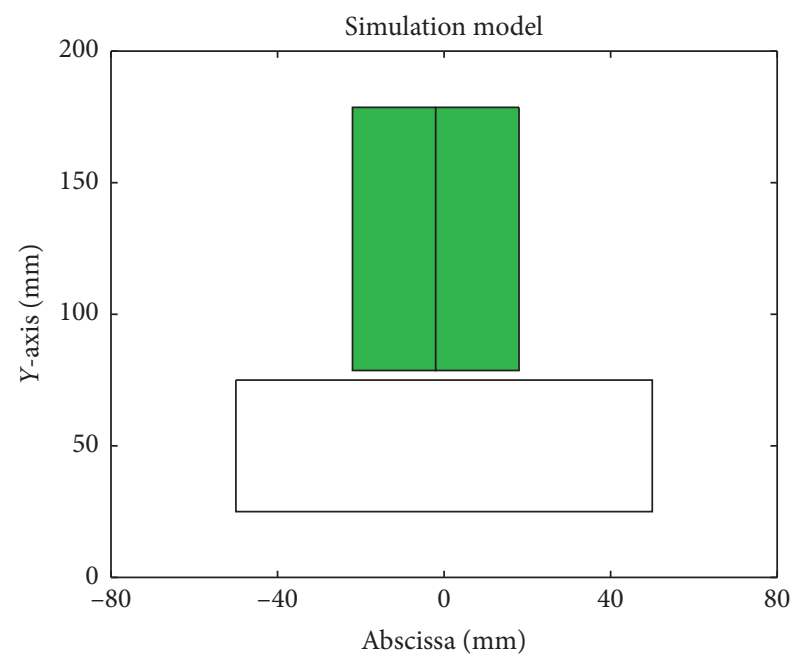

Figure 3: Two-dimensional model of multimaterial electrode workpiece machining.

(5) Short circuit, debris accumulation and secondary discharges, the influence of the distribution of debris on discharge probability, the influence of secondary discharge on the shape change of electrode side, the influence of discharge state on the volume of removal material, the thermal and physical factors of working liquid, the influence of environmental temperature change, and flushing liquid are not considered.

According to the above analysis of modeling, the simulation electrode of multimaterial electrode EDM adopts a two-dimensional model along the central axis, and the corresponding processing workpiece also adopts a two-dimensional model. The two-dimensional model size of the electrode and workpiece is the same as that of the multimaterial electrode experiments. The multimaterial electrode machining model established in MATLAB is shown in Figure 3.

2.2. Simulation Parameter Settings and Process Analysis. The EDM multimaterial electrode is composed of different electrodes with diameters of $2 \mathrm{~mm}$. When two materials are combined, the size of the electrode is $4 \mathrm{~mm} \times 10 \mathrm{~mm}$; when three materials are combined, the size of the electrode is $10 \mathrm{~mm} \times 6 \mathrm{~mm}$. The size of the workpiece is $10 \mathrm{~mm} \times 4 \mathrm{~mm}$. Other parameters used in MATLAB are shown in Table 1.

Figure 4 shows the multimaterial electrode simulation flowchart based on the powerful calculation function of MATLAB software. By setting the single-pulse removal volume of electrodes and the electrode workpiece wear ratio and other simulation parameters, multimaterial electrode shape change simulation analysis can be conducted. After the model is established, the basic simulation parameters of the model are set, including meshing. The removal volume obtained by ANSYS of each material and the relative wear ratio of the electrode workpiece are input whose correctness has been verified by experiments. The following work is mainly about the identification of discharge boundary, determination of the position of the discharge point, and selection of the removal strategy so as to simulate the process of shape change in EDM of the multimaterial electrode.

2.3. ANSYS Simulation and Calculation of Single-Pulse Removal Volume. The removal volume of single pulse of each electrode and the wear ratio of electrode and workpiece are obtained by ANSYS simulation and experiment. In the simulation, the element deactivation method is used to simulate the removal result of pulse discharge in multimaterial electrode EDM. The material removal volume in single-pulse multimaterial electrode simulation can be obtained by multiplying the number of removal elements by the actual volume represented by each element. Simulation parameters of single-pulse removal volume are shown in Table 2. The simulation parameters selected in Table 2 are the same as the actual processing parameters.

The continuous machining experiments of brass, copper, and C45 were carried out on the multimaterial electrode EDM machine with the same parameters as the simulation calculation. Finally, the removal volume of each material in the experiment under a single pulse is calculated, which can be obtained by the following equations: 
TABLE 1: Basic parameters of MATLAB simulation.

\begin{tabular}{lc}
\hline Parameters & Description \\
\hline Mesh size $(\mu \mathrm{m})$ & $1 \times 1$ \\
Discharge gap $(\mu \mathrm{m})$ & 5 \\
Simulation time step $(\mu \mathrm{s})$ & 20 \\
Feeding speed $(\mu \mathrm{m} / \mathrm{s})$ & 1 \\
Processing time $(\mathrm{min})$ & 3 \\
Electrode materials & Brass, copper, C45 \\
Multimaterial electrode & Brass-copper, C45-brass-copper, \\
Workpiece material & Die steel \\
\hline
\end{tabular}

$$
\begin{aligned}
n & =\frac{t}{T}, \\
V_{2} & =\frac{V}{n},
\end{aligned}
$$

where $t$ is the machining time $(\mu \mathrm{s})$; $T$ is the sum of pulse-on and pulse-off $(\mu \mathrm{s}) ; n$ is the number of discharge cycle; $V_{2}$ is the actual removal volume of a single-pulse material $\left(\mu \mathrm{m}^{3}\right)$; and $V$ is the total volume removed by processing time $t$.

According to the above analysis and calculation, the volume and relative wear ratio of each electrode material are obtained by single-pulse removal as shown in Table 3 .

2.4. Update Identification of Discharge Boundary of Multimaterial Electrode Workpiece. The numerical operation is performed in MATLAB, which requires the connection between the two-dimensional model and the numerical value. The boundary of the model between the electrode and the workpiece needs to be shown in MATLAB. The initial discharge boundary is the lower surface of the electrode and the upper surface of the workpiece. Figure 5 shows the discharge boundary of the multimaterial electrode workpiece model. According to Figure 5, the discharge boundary of the multimaterial electrode and workpiece is different when discharging. The lower boundary of the electrode and the upper boundary of the workpiece shown in Figure 5 are the initial discharge boundary. The discharge boundary changes correspondingly with the machining. Then, the recognition function in MATLAB is used to identify the coordinates of the lower edge points of the electrode and the coordinates of the upper edge points of the workpiece for the determination of the discharge boundary position of the multimaterial electrode and the workpiece in MATLAB. As the machining goes on, the discharge boundary will change because the electrode and workpiece will be removed. The boundary recognition function in MATLAB is used to track the boundary and update the discharge boundary. At the discharge boundary, different discharge points are selected to complete the discharge machining according to the selection and removal strategy of discharge points.

\subsection{Discharge Location Selection and Removal Strategy.} The coordinate value of the boundary function is stored in the register. With the calculation of electrode feeding, the position of coordinate points is updated after material removal, and discharge points are selected in the process of the multimaterial electrode in EDM. (1) Determination of initial discharge area and discharge point. It is necessary to determine the material composition of the multimaterial electrode and select the discharge electrode according to the different probabilities of thermal field electric breakdown and the electric work function. After selecting the discharge electrode, the discharge distance between the electrode and the workpiece is the same, and the random discharge selection is made. However, considering the actual machining edge effect, the shortest distance between the discharge electrode and the workpiece edge is selected as the discharge point in EDM. (2) Determination of discharge point after continuous machining discharge. In the machining process, different materials are alternately discharged. The electrode area is distinguished according to the value of the identified horizontal coordinate. After continuous discharge machining, the shortest distance position of the electrode workpiece is recalculated. At this point, there will be several shortest distance discharge points. There are two cases: when the minimum distance appears on different materials at the same time, the material with less electron work function and higher breakdown probability is set to discharge first; when multiple minimum distances appear on the same material at the same time, one of the shortest distances as the discharge point is randomly selected. (3) A single discharge material removal strategy for the multimaterial electrode. In the process of multimaterial electrode simulation, only one discharge crater is generated at each electrode for each discharge, and the volume of a single discharge is equal to the removal volume of a single-pulse discharge. The removal volume of the electrode and workpiece is determined by the removal volume and relative wear ratio of the electrode and workpiece by single-pulse discharge. (4) Continuous discharge removal strategy. After continuous discharge, the shortest discharge distance appears on different materials of the multimaterial electrode, and the discharge removal volume will have an overlap condition. If there is no overlap between materials 1 and 2, each material is removed separately. If there is an overlap between material 1 and material 2 where two discharges occur, the volume removed by the overlap is subtracted. Figure 6 shows the removal strategy of the workpiece, and Figure 7 shows the removal strategy for the multimaterial electrode material.

2.6. Experimental Designs of Multimaterial Electrode Continuous Discharge Machining. To verify the effectiveness of the electrode material simulation model and analysis of different combination materials of electrode shape change law, a variety of multimaterial electrodes are designed by combining copper, brass, and C45. The electrode materials and their processing parameters are shown in Table 4 . The electrode materials shown in Table 4 are combined according to the requirements. Different electrode materials are connected in different order by the hot tin plating method to make the multimaterial electrode. First, the 


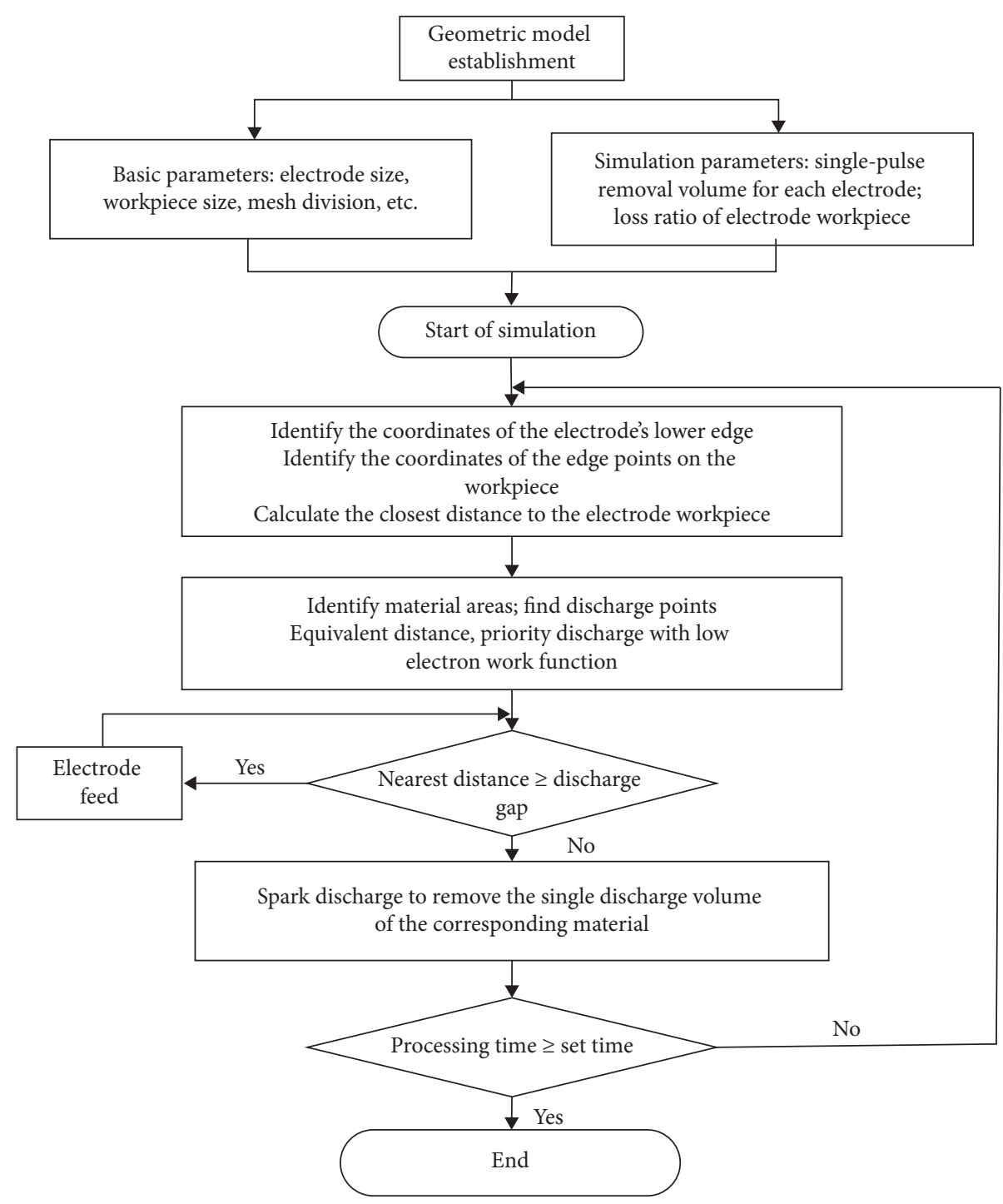

Figure 4: Multimaterial electrode simulation flowchart.

TABLE 2: Simulation parameters of single-pulse removal volume in ANSYS.

\begin{tabular}{lc}
\hline Parameters & Description \\
\hline Voltage $(\mathrm{V})$ & 45 \\
Current $(\mathrm{A})$ & 0.8 \\
The grid size $(\mu \mathrm{m})$ & $1 \times 1$ \\
Electrode materials & Brass, copper, C45 \\
The heat source & Gaussian heat flux density \\
The workpiece material & Die steel \\
\hline
\end{tabular}

electrodes are tied together. Secondly, the tin is heated to liquid and dropped on the electrodes. Finally, after the tin is cooled, the electrodes are welded, as shown in Figure 8.

The prepared multimaterial electrode is set to a constant value by machining time, and the multimaterial electrode forming process is performed. The shape of the multimaterial electrode after machining was observed by an electron microscope and compared with the simulation results, and the shape change law of the multimaterial electrode was studied.

\section{Multimaterial Electrode Simulation Results and Experimental Results}

3.1. Comparison and Analysis of Multimaterial Electrode Simulation and Experimental Results for Two Materials. Figure 9 shows a comparison of simulation and experimental results for multimaterial electrodes with two materials. In Figures 9(a) and 9(b), the left side is copper and the right side is brass. MATLAB boundary recognition function is used to compare the simulated extraction curves of multimaterial electrodes and the experimental identification curves, as shown in Figure 9(c). According to the comparison between simulation and experiment shown in Figure 9, the shape of the electrode wear calculated by the simulation model is basically consistent with the wear shape of the actual machining electrode. This shows that it can accurately predict the shape change of multimaterial electrodes and proves the effectiveness of the simulation model. By comparing Figure 8 with simulation and experiment, it can be seen that the wear of the brass electrode after 
TABLE 3: Single-pulse removal volume and relative wear ratio of electrode materials.

\begin{tabular}{lccc}
\hline Material & Single-pulse removal volume, $V_{2}\left(\mu \mathrm{m}^{3}\right)$ & Electrode workpiece relative wear ratio (\%) & Electron escape work (eV) \\
\hline Brass & 150 & 18 & $3.34-5.24($ take 3.34$)$ \\
Copper & 180 & 22 & 5.24 \\
C45 & 175 & 24 & 4.47 \\
\hline
\end{tabular}

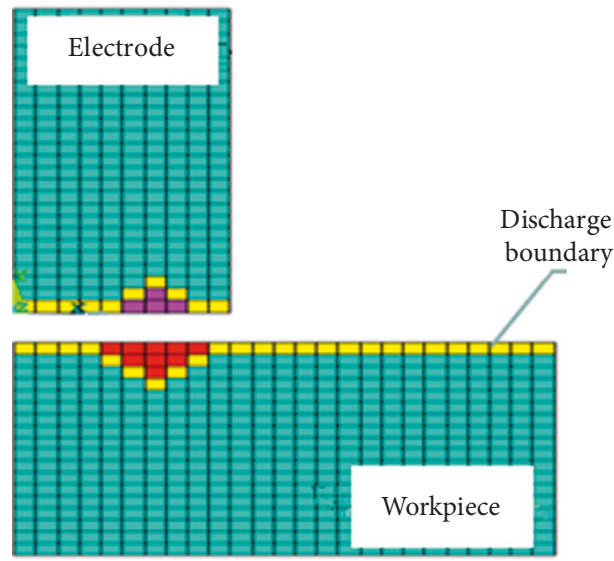

FIGURE 5: Multimaterial electrode discharge boundary.

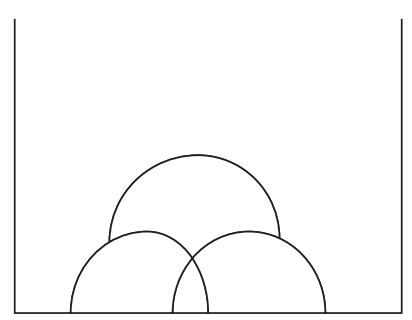

(a)

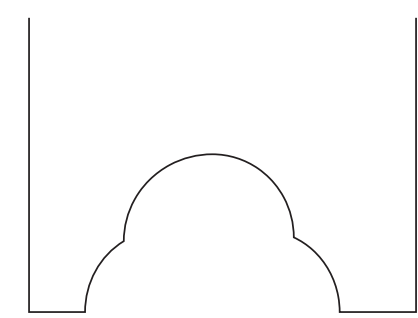

(b)
FIGURE 6: Material removal strategy by simulation in workpiece discharge. (a) Intersectional volume removal. (b) Material removal by simulation.

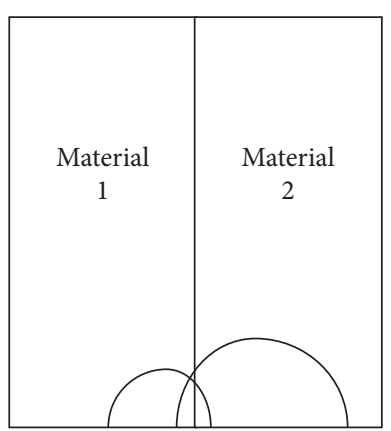

(a)

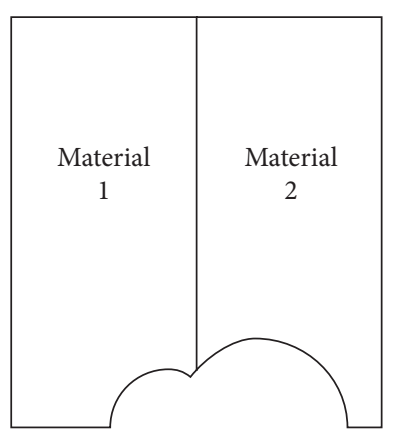

(b)
FIgURE 7: Material removal strategy by simulation in multimaterial electrode discharge. (a) Intersectional volume removal. (b) Material removal by simulation.

machining is smaller than that of copper, and the depth of the workpiece of the brass electrode is greater than that of copper. The main reason for this phenomenon is that the
TABle 4: Multimaterial electrode materials and processing parameters.

\begin{tabular}{lc}
\hline Parameters & Description \\
\hline Multimaterial electrode & Brass-copper, copper-C45-brass, \\
Workpiece material & C45-copper-brass \\
Machining polarity & NAK80 die steel \\
Time-on $(\mu \mathrm{s})$ & Positive polarity \\
Time-off $(\mu \mathrm{s})$ & 12.5 \\
Breakdown voltage $(\mathrm{V})$ & 7.5 \\
Peak current $(\mathrm{A})$ & 45 \\
Electrode diameter $(\mathrm{mm})$ & 0.8 \\
Processing time $(\mathrm{min})$ & 2 \\
Working liquid & 3 \\
\hline
\end{tabular}

wear of multimaterial electrodes under the same machining conditions is influenced by the volume of singlepulse removal, the relative wear ratio of the electrode workpiece, and the electron work function. The singlepulse removal volume mainly affects the wear of the electrode. The relative wear ratio of the electrode workpiece mainly affects the depth of the electrode machining, and the electron work function affects the discharge probability after the continuous discharge processing. According to Table 3, the single-pulse removal volume of the brass electrode is smaller than that of copper. So, under the same discharge probability, the wear of brass after continuous EDM is smaller than that of copper. Because the relative wear ratio of copper is greater than that of brass, when machining the same workpiece material, the wear volume of red copper is larger than that of brass. After the continuous electrical discharge machining, the depth of the cavity on the workpiece of the copper is smaller than that of brass. The above two reasons determine that the wear of the brass electrode is smaller than that of copper, and the depth of the cavity on the workpiece of the brass electrode is greater than that of copper after machining. According to Table 3, the electron work function of brass is smaller than that of copper. After the continuous discharge, the probability of discharge of brass is greater than that of copper. However, the overall material wear is smaller because the single removal volume of brass and the relative wear of the electrode workpiece are smaller.

Comparing the simulation results and the experimental results shown in Figure 9, a multimaterial electrode composed of brass and copper has formed a transitional surface at the junction of the two material electrodes after machining. This is mainly due to the results of the interaction between the properties of different materials. However, from the comparison between the simulation curve and the 


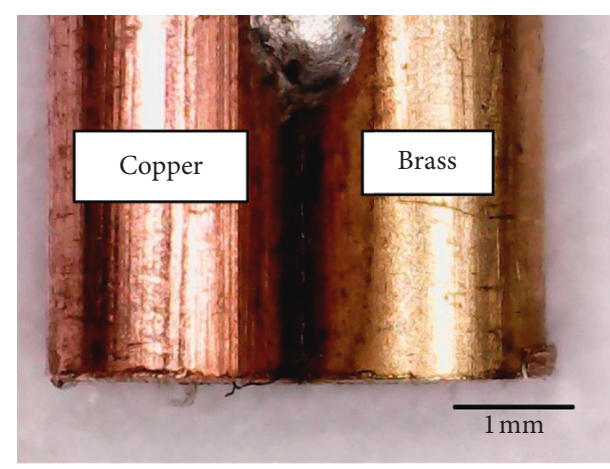

(a)

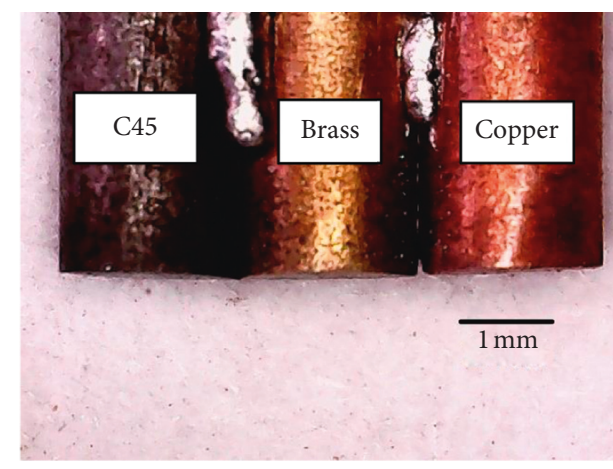

(b)

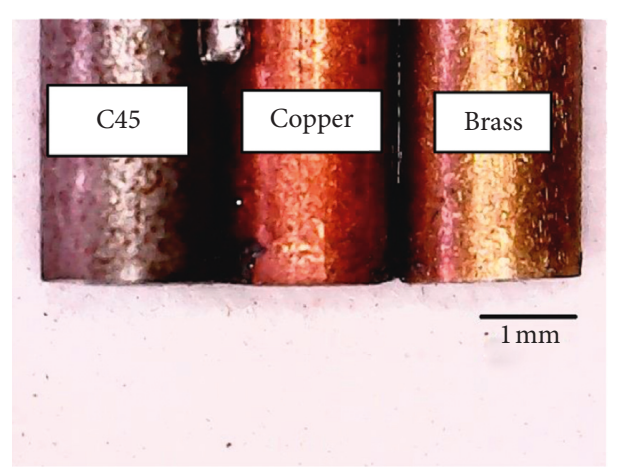

(c)

Figure 8: Different composite multimaterial electrodes before processing. (a) Copper-brass multimaterial electrode. (b) C45-brass-copper multimaterial electrode. (c) C45-copper-brass multimaterial electrode.

experimental curve, it can be seen that there is also a certain deviation between the two materials, and the transition surface at the connection in the simulation result is not as smooth as the transition in the experimental result. The similarity between simulation and experimental curves is compared. $R$ square (coefficient of determination) analysis is used, and the result of $R$-square is 0.96 . The value is close to 1 , which means the similarity of simulation and experiment is excellent. And the curve at the edge in the simulation is not as smooth as the experimental curve at the edge. The main reason is that there is debris in the working medium that induces discharge breakdown (secondary discharge phenomenon), which will remove the sharp corners and edges to the electrode. The simulation did not consider the phenomenon of secondary discharge, resulting in the deviation of simulation and experiment. In fact, the reason is not only secondary discharge but also the distortion of electric field at sharp corners and edges during discharge, which leads to concentrated distribution of electric field intensity, thus increasing the probability of local discharge and causes sharp corners and edges to be worn first, and it is also a cause of deviation.

\subsection{Comparison and Analysis of Multimaterial Electrode} Simulation and Experimental Results for Three Materials. Figures 10 and 11 show simulations and experimental comparisons of the shape changes of copper-brass-C45 and C45copper-brass multimaterial electrodes, respectively. According to Figures 10 and 11, comparing the simulation and experimental results of the multimaterial electrode composed of these three materials, the overall shape of the multimaterial electrodes predicted by the simulation is substantially consistent with the actual machining results, indicating that the multimaterial electrode composed of these three materials in the simulation has a good accuracy. By observing Figures 10 and 11, the overall trend of electrode wear is C45>copper $>$ brass regardless of the combination order of materials. This is mainly related to the factors such as the single-pulse removal volume of the electrode, the relative wear ratio of the electrode workpiece, and the electron work function of the material.

The main reason that the wear of copper is greater than that of brass is the same as the reason mentioned in Section 3.1. And the main reason that the wear of $\mathrm{C} 45$ is greater than that of copper is the single-pulse removal volume of C45 is smaller than that of copper, but the two are similar. And the relative wear ratio of the electrode workpiece of C45 material is greater than that of copper; therefore, when the removal volume is the same, the C45 electrode removes less material on the workpiece than that of copper, and this also makes the distance between the C45 electrode and the workpiece material closer, increasing the probability of secondary discharge. Because the electron work function of C45 is smaller than the copper, after continuous discharge, the probability of discharge of C45 material is greater than that of copper, which increases the wear of C45 electrode. Therefore, the electrode wear of C45 after continuous discharge is greater than that of copper.

By observing Figures 10 and 11, the multimaterial electrodes of the same material combination will have 


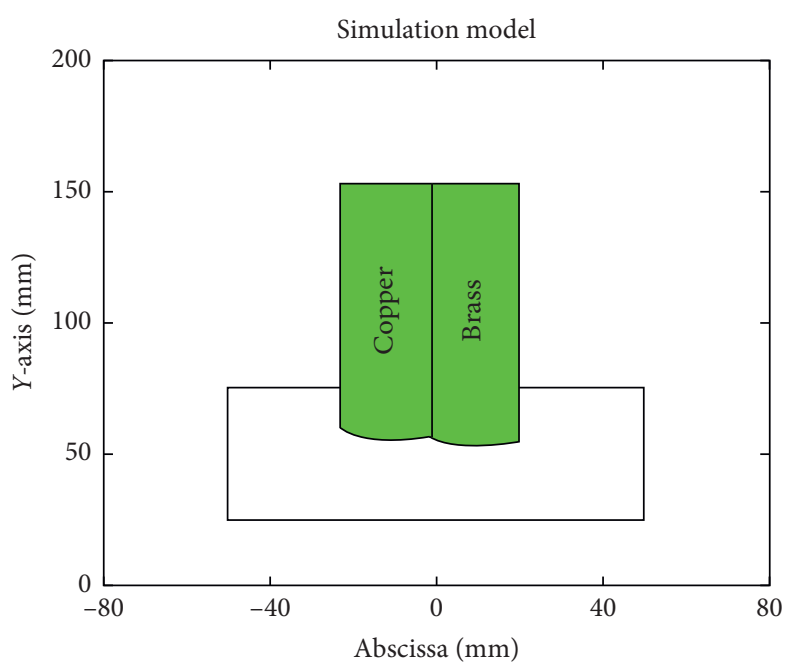

(a)

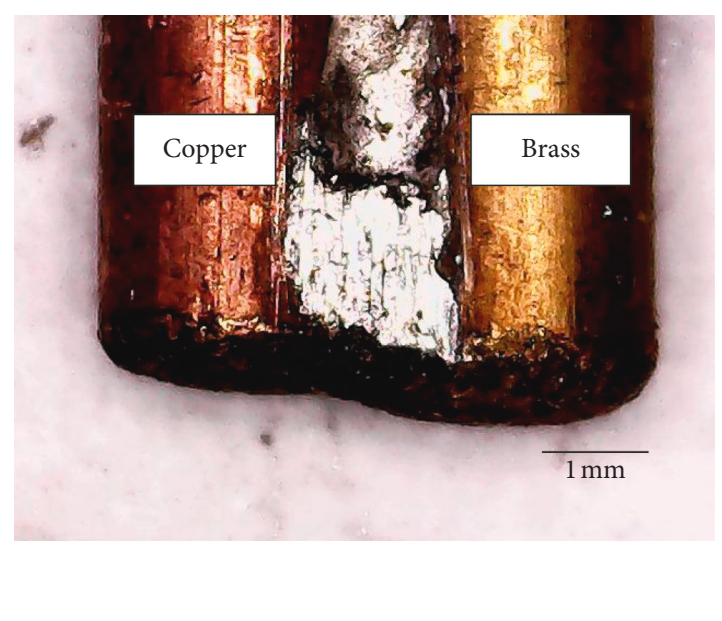

(b)

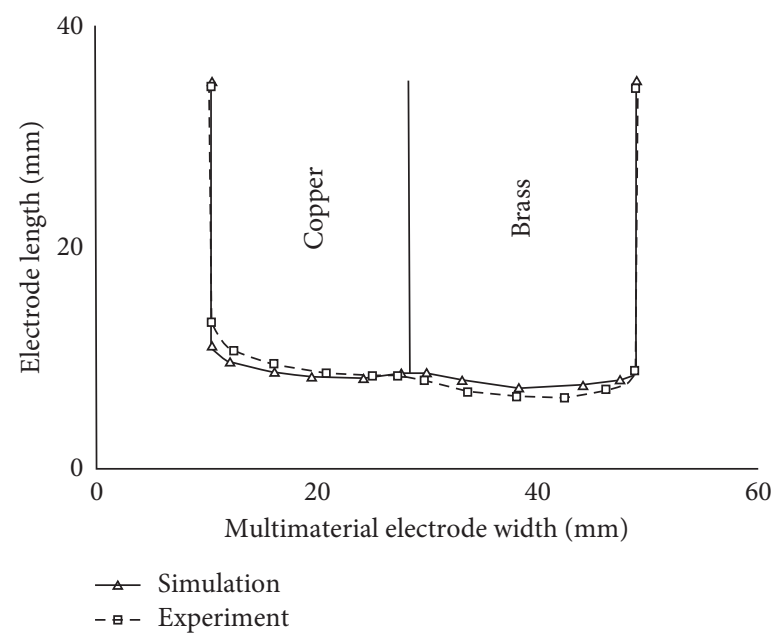

(c)

Figure 9: Comparison of simulation and experimental results of multimaterial electrodes for two materials. (a) Copper-brass simulation results. (b) Copper-brass experimental results. (c) Simulated extraction curve and experimental identification curve.

different shape changes after machining due to the different combination orders among the materials. The end face of the C45 electrode is relatively straight, and there is a certain circular arc at the end of the copper wear, but it is not obvious, and the end face of the brass is arc-shaped. This is mainly because during machining, the deeper the depth of processing is, the greater the probability of secondary discharge occurs during discharge of the debris, which increases the edge wear of the electrode and forms a fillet at the sharp edges of the electrode. According to Figures 10 and 11, at the junction of the multimaterial electrodes, no matter how the electrodes are combined, corresponding transition surfaces are generated. Comparing the curved surfaces with the two connected areas shown in Figures 10(b) and 11(b), the wear and shape of the multimaterial electrode are different. It can be seen that the arc formed between C45 and brass is smaller than the arc between C45 and copper. This is mainly related to the different wear characteristics of multimaterial electrode materials. Comparing Figures 10(b) and 11(b), it can be seen that the wear of C45 and copper is not much different, and the arc at the junction after continuous processing is larger. The wear of $\mathrm{C} 45$ is very different from that of brass, so the arc formed at the junction of the two materials after continuous discharge is small. In addition, the curvature of the junction between brass and copper shown in Figure 11(b) is smaller than the arc of the junction between copper and brass shown in Figure 10(b). This is mainly due to the fact that compared with Figure 10(b), the wear of copper shown in Figure 11(b) has increased, resulting in a greater wear difference between the copper and the brass in Figure 11(b) than that in Figure 10(b). The arc at the junction after continuous discharges is smaller. The similarity between simulation and experimental curves is compared. The result of $R$-square shown in Figure 10(c) is 0.90, and in Figure 11(c), it is 0.92 . The value is close to 1 , which means the curve in simulation and experiment is excellent.

In summary, the multimaterial electrode shape changes simulation model proposed in this paper can better simulate 

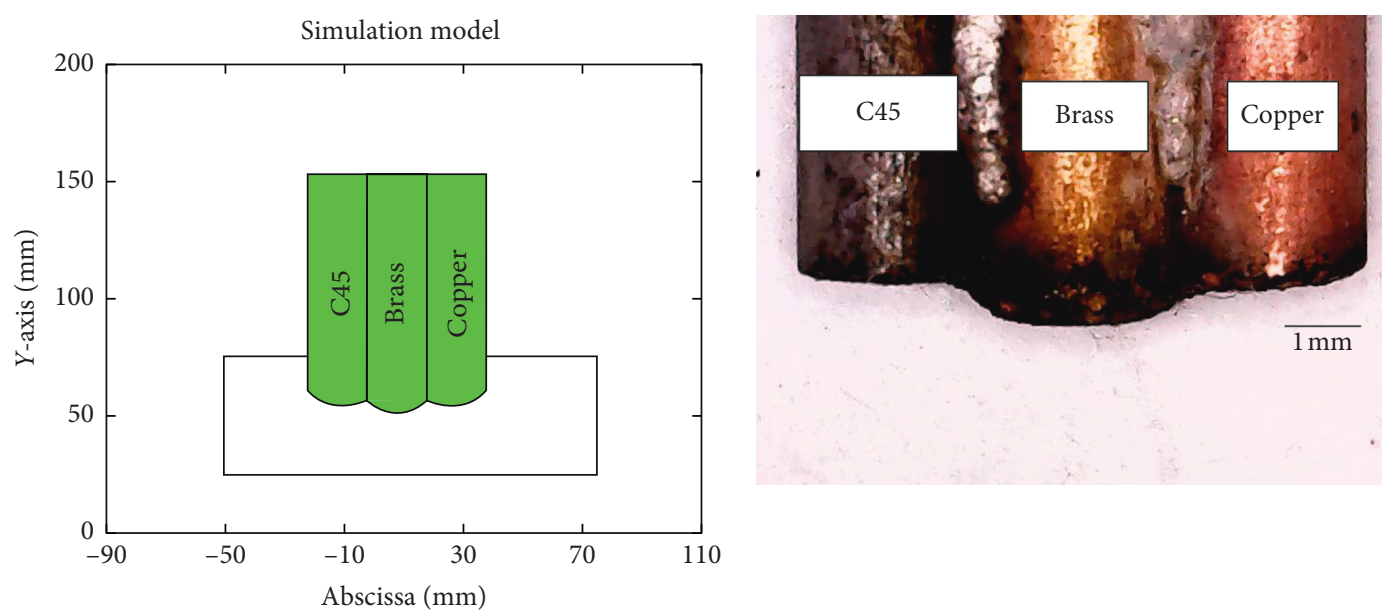

(a)

(b)

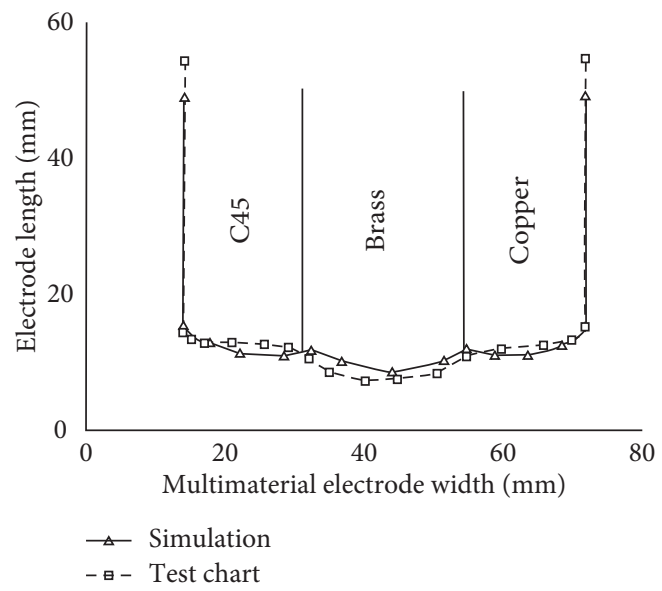

(c)

FIgURE 10: Comparison of the simulation and experimental results of copper-brass-C45 multimaterial electrodes. (a) C45-brass-copper simulation results. (b) C45-brass-copper experimental results. (c) Simulation extraction curve and experimental identification curve.

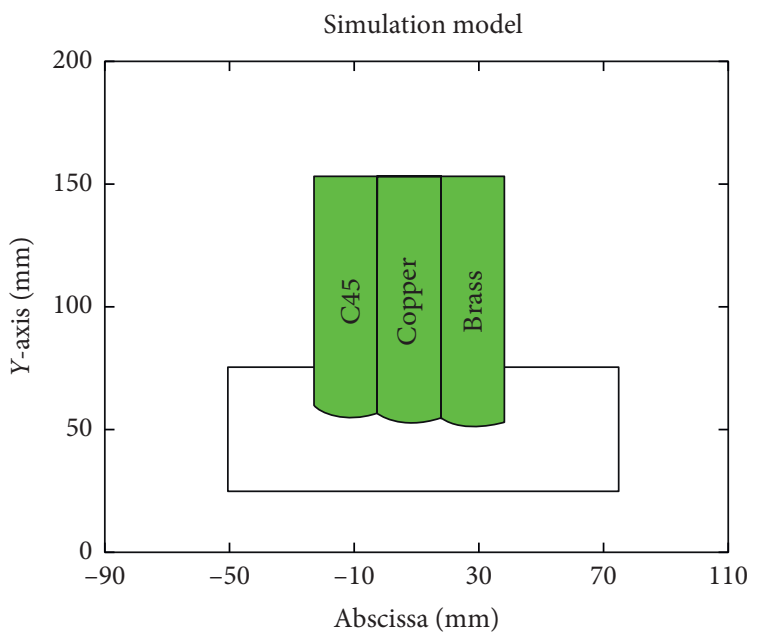

(a)

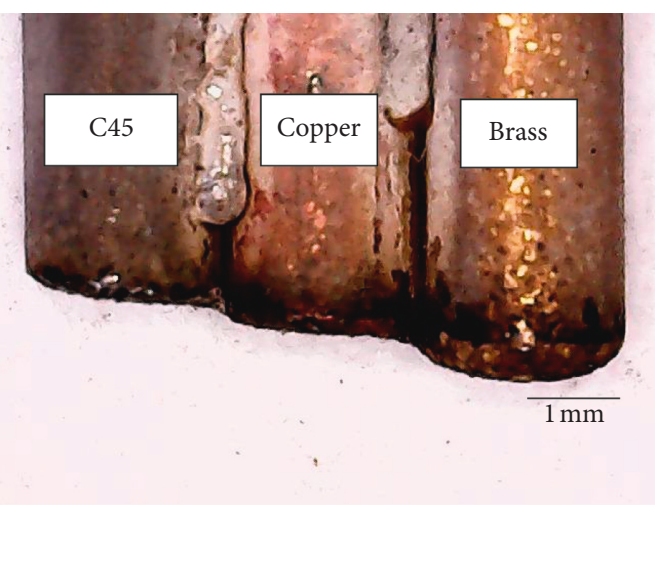

(b)

Figure 11: Continued. 


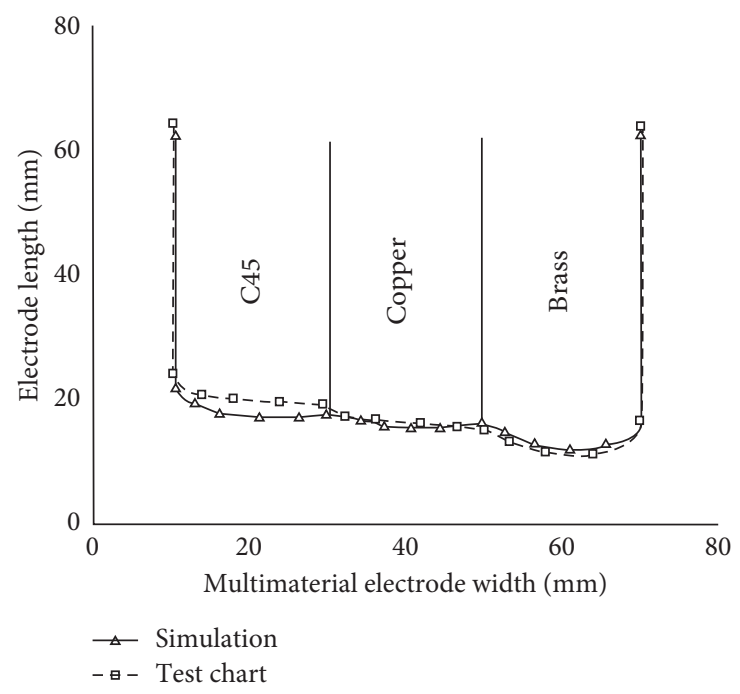

(c)

Figure 11: Comparison of the simulation and experimental results of C45-copper-brass multimaterial electrodes. (a) C45-copperbrass simulation results. (b) C45-copper-brass experimental results. (c) Simulation extraction curve and experimental identification curve.

the whole shape change trend of the multimaterial electrode in machining and can predict the shape change of different combinations of multimaterial electrodes and then predict the shape of a complex curved surface with multimaterial electrodes.

\section{Conclusions}

In this paper, the shape change rules of multimaterial electrodes for EDM using the continuous discharge simulation method and single factor experimental method are discussed. The shape change of multimaterial electrodes with different electrode material combinations was analyzed. Comparing the simulation results with the experimental results, the following conclusions can be obtained:

(1) EDM shape change simulation was carried out using MATLAB. By setting simulation parameters such as single removal volume, relative wear rate, and electron work function of different materials, it is possible to effectively simulate the multimaterial electrode shape change process and predict the final electrode shape. $R$-square analysis of the difference between the simulation and the experimental data shows that the $R$-square of the copperbrass multimaterial electrode is 0.96 , and the $R$ square of the copper-brass-C45 and C45-copperbrass multimaterial electrode is 0.90 and 0.92 , respectively, which verifies the good fitness of the two curves.

(2) In the process of the multimaterial electrode for two materials, the less the single-pulse removal volume is, the less the electrode workpiece relative wear ratio is and the less the electrode wear is. The discharge breakdown probability of materials with lower electron work function is larger, which can promote machining efficiency and increase electrode wear. However, single-pulse removal volume and the electrode workpiece relative wear ratio of materials play more significant role than their electron work function.

(3) When machining with multimaterial electrodes using a combination of three materials, different material combination orders will produce different shape changes. For materials with similar wear volume, the transitional arc at the junction of the two materials is relatively large. For materials with large differences of wear volume, the transitional arc at the junction of the two materials is relatively small. When one material is combined with different materials, the shape of the junction will also be slightly different.

\section{Data Availability}

The data used to support the findings of this study are available from the corresponding author upon request.

\section{Conflicts of Interest}

The authors declare that there are no conflicts of interest regarding the publication of this paper.

\section{Acknowledgments}

The financial support from the National Natural Science Foundation of China under grant no. 51875074, College-Level Project of Shaanxi Railway Institute under grant no. KY2018-82, and General Program of Natural Science Foundation of Liaoning Province under grant no. 20180550425 is acknowledged. 


\section{References}

[1] B. Mohan, K. G. A. Rajadurai, and K. G. Satyanarayana, "Electric discharge machining of $\mathrm{Al}-\mathrm{SiC}$ metal matrix composites using rotary tube electrode," Journal of Materials Processing Technology, vol. 153-154, pp. 978-985, 2004.

[2] P. Kuppan, A. Rajadurai, and S. Narayanan, "Influence of EDM process parameters in deep hole drilling of Inconel 718," International Journal of Advanced Manufacturing Technology, vol. 38, no. 1-2, pp. 74-84, 2008.

[3] P. M. George, B. K. Raghunath, L. M. Manocha, and A. M. Warrier, "EDM machining of carbon-carbon composite-a Taguchi approach," Journal of Materials Processing Technology, vol. 145, no. 1, pp. 66-71, 2004.

[4] Y. H. Jeong and B.-K. Min, "Geometry prediction of EDMdrilled holes and tool electrode shapes of micro-EDM process using simulation," International Journal of Machine Tools and Manufacture, vol. 47, no. 12-13, pp. 1817-1826, 2007.

[5] E. Uhlmann and M. Roehner, "Investigations on reduction of tool electrode wear in micro-EDM using novel electrode materials," CIRP Journal of Manufacturing Science and Technology, vol. 1, no. 2, pp. 92-96, 2008.

[6] A. Surleraux, J.-P. Pernot, A. Elkaseer, and S. Bigot, "Iterative surface warping to shape craters in micro-EDM simulation," Engineering with Computers, vol. 32, no. 3, pp. 517-531, 2016.

[7] Z. Y. Yu, J. Kozak, and K. P. Rajurkar, "Modelling and simulation of micro EDM process," CIRP Annals, vol. 52, no. 1, pp. 143-146, 2003.

[8] J. Pei, Z. Zhou, X. Zhuang et al., "Study on the forming of the cone-shaped electrode in micro-EDM milling with fix-length compensation method," in Proceedings of the 4M/ ICOMM2015 Conference, Milan, Italy, 2015.

[9] Q. C. Lv, Simulation and Experimental Study on the Fabrication of the Composite Electrode for MEDM, Dalian University of Technology, Dalian, China, 2009, in Chinese.

[10] Y. L. Fu, Y. M. Zhu, W. S. Zhao et al., "Geometry simulation and study on electrode tool wear in micro EDM," Electromachining and Mould, vol. 1, pp. 6-9, 2016, in Chinese.

[11] A. K. Khanra, B. R. Sarkar, B. Bhattacharya, L. C. Pathak, and M. M. Godkhindi, "Performance of $\mathrm{ZrB2}-\mathrm{Cu}$ composite as an EDM electrode," Journal of Materials Processing Technology, vol. 183, no. 1, pp. 122-126, 2007.

[12] N. Mohri, Y. N. Saito, and N. Kinoshita, "Metal surface modification by electrical discharge machining with composite electrode," CIRP Annals, vol. 42, no. 1, pp. 219-222, 1993. 


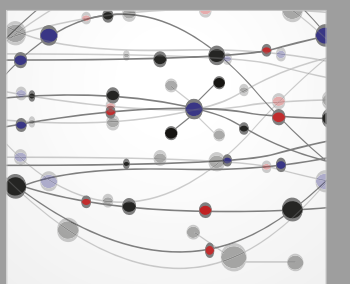

The Scientific World Journal
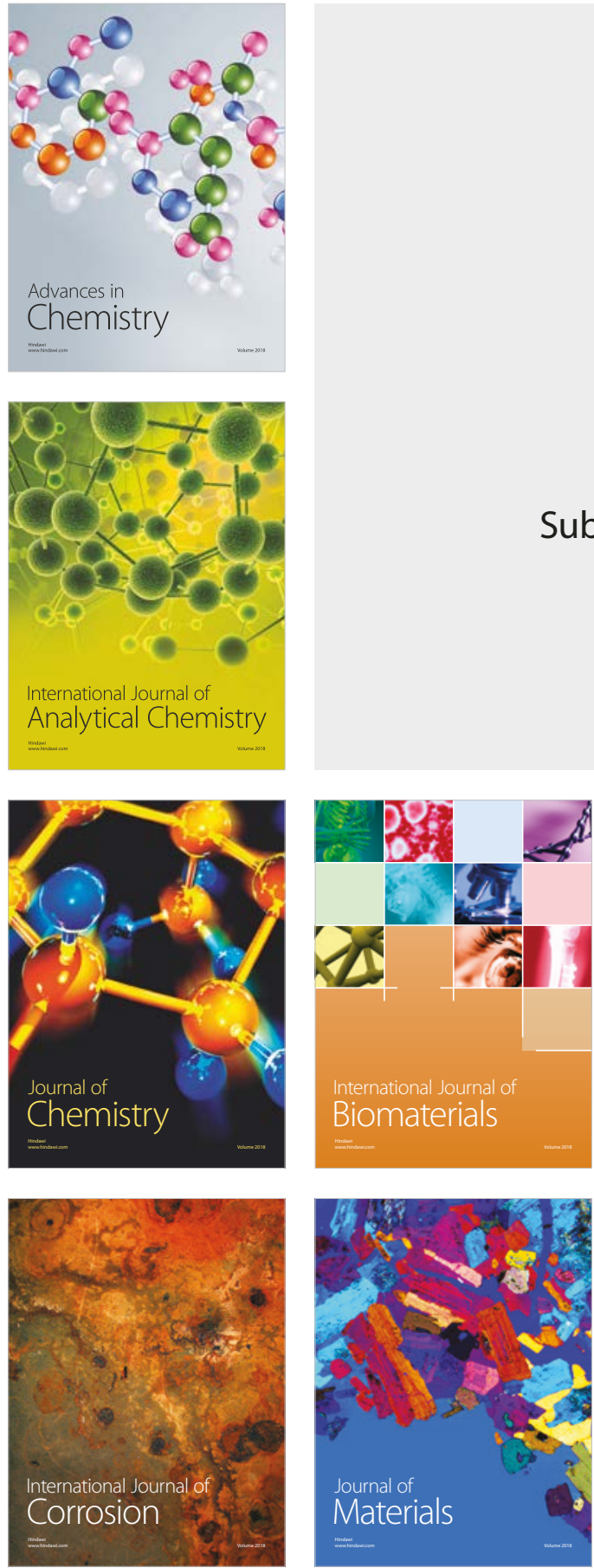

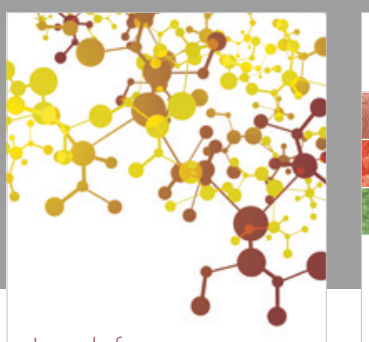

Journal of

Applied Chemistry
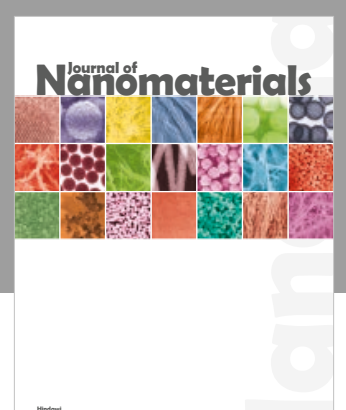

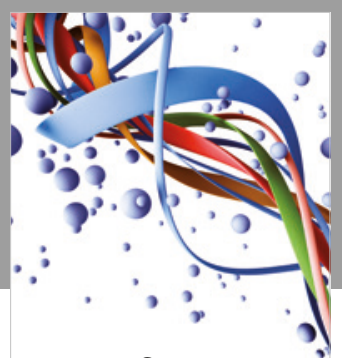

Scientifica

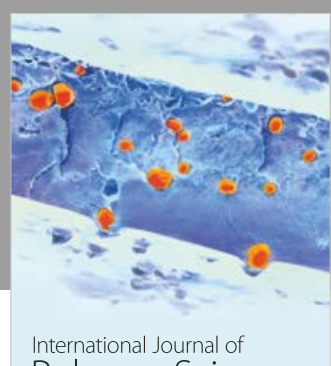

Polymer Science

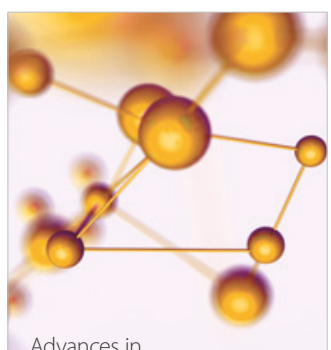

Physical Chemistry
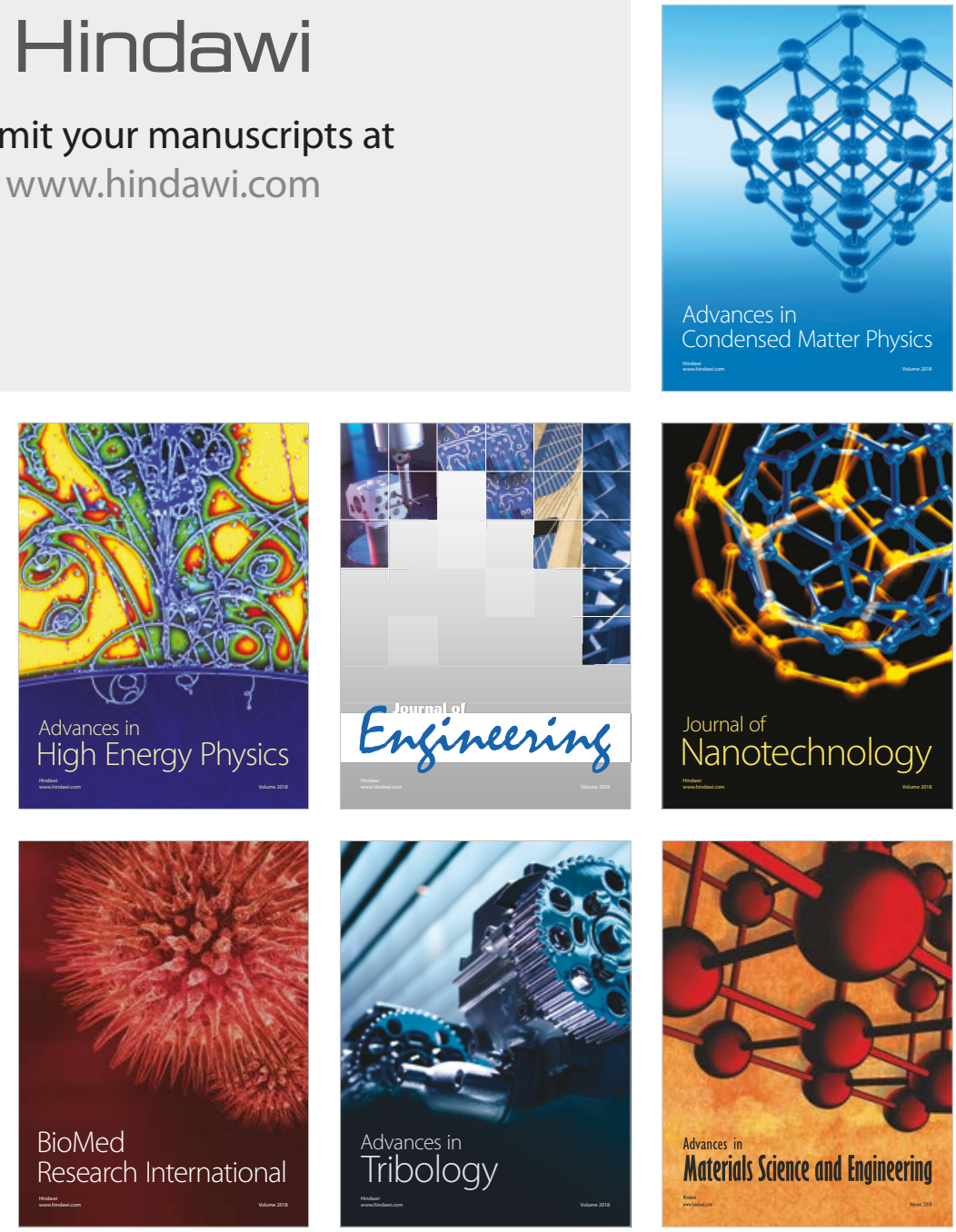